\title{
APOL1 Gene - Implications for Systemic Lupus Erythematosus
}

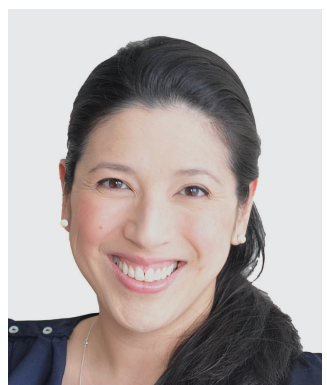

It is well recognized that African Americans of sub-Saharan African ancestry have nearly a 4-fold increased prevalence of endstage kidney disease (ESKD) over European Americans ${ }^{1,2,3,4}$. In 2008, two coding alleles in the apolipoprotein L1 gene (APOL1), G1 and G2, were discovered to account for the majority of excess risk in progressive nondiabetic kidney disease in African Americans 1,2,3,5. The several forms of APOL-1-associated kidney disease include focal segmental glomerulosclerosis (FSGS), human immunodeficiency virus-associated nephropathy (HIVAN), hypertension-attributed ESKD, and sickle cell nephropathy $5,6,7,8$. There is a strong biallelic effect observed such that a high-risk genotype defined as the presence of 2 APOL1 risk alleles confers the strongest risk for HIVAN in the United States ${ }^{7}$ with an OR of 29 (95\% CI 13-68), and an OR of 89 (95\% CI 18-912) in South Africa9 ${ }^{9}$ This observation of stronger adverse kidney outcomes associated with $A P O L 1$ risk alleles was the rationale for a report by Vajgel, et $a l^{10}$ that appears in this issue of The Journal.

Their study involved genotyping APOL1 G1 and G2 risk alleles in 201 nonwhite Brazilian patients with lupus nephritis (LN) and 222 healthy blood donors. Because of the low APOL1 biallelic frequency in LN cases (2\%), the authors had limited power to test biallelic effects and instead examined monoallelic APOL1 risk allele effect on LN outcomes. The authors observed a higher prevalence of $\mathrm{LN}$ patients with lower estimated glomerular filtration rates (eGFR; chronic kidney disease stages 4 and 5) of persistent duration ( $>6 \mathrm{mos}$ ) in those with 1 APOL1 risk allele compared to those with none ${ }^{10}$.

The Vajgel, et al findings are consistent with prior studies of $A P O L 1$ risk allele effects on $\mathrm{LN}$ renal functional outcomes. In a study of 855 African American systemic lupus erythematosus (SLE) patients with LN-ESKD and 534 African American SLE patients without nephritis, APOL1 high-risk genotype was associated with progression to ESKD, with an OR 2.72 (95\% CI 1.76-4.19, p = 6.23 $\times$ $\left.10^{-6}\right)^{3}$. That study also reported a shorter time from SLE onset to ESKD among those with an APOL1 high-risk genotype $(5.5 \pm 6.1 \mathrm{yrs})$ compared to those with 1 or no risk alleles $(7.9 \pm 7.3 \mathrm{yrs}, \mathrm{p}=0.01)^{3}$. Yet Vajgel, et al's study ${ }^{10}$, and other studies, observed no association between APOL1 risk alleles and LN risk itself, assuming sufficient power to detect an effect on LN risk similar to that on ESKD ${ }^{11,12}$.

In African Americans, the APOL1 risk allele frequency is about $36 \%$ and the prevalence of the high-risk APOL1 genotype is $13 \%{ }^{6,13}$. In the Brazilian nonwhite population studied by Vajgel, et al, the $A P O L 1$ risk allele frequency was $9 \%$ among patients with $\mathrm{LN}$, and $8 \%$ among non-SLE controls $(\mathrm{p}=0.44)$. This high frequency of alleles with large effects suggests that natural selection for the beneficial APOL1 effects is at play. Circulating APOL1 likely kills the trypanosome by lysis ${ }^{14}$. This includes the parasite Trypanosoma brucei rhodesiense causing trypanosomiasis (African sleeping sickness), which evolved to develop a virulence factor, serum-resistant activity (SRA). SRA binds to and inactivates APOL1, enabling the parasite to escape the human, host defenses and survive. High-risk APOL1 genetic variants result in an encoded APOL1 protein, protected from SRA binding, providing a selective advantage ${ }^{4,13}$.

The high frequency of APOL1 GI and G2 alleles is also in part due to incomplete penetrance of their deleterious renal effects. Most people carrying the high-risk genotype never develop significant kidney disease ${ }^{4,7}$. This observation along with the recognition that $A P O L 1$ progressive CKD spans different systemic diseases suggests the possibility of a "2-hit" pathogenic process ${ }^{4}$. A potential second hit interacting with $A P O L 1$ risk genotype may be systemic disease such as HIV or SLE ${ }^{15}$.

Both HIV infections and SLE are diseases characterized by elevated type I interferon (IFN). HIV is a potent inducer of IFN and other innate antiviral immune responses. SLE is a type I IFN-driven autoimmune disease. There have also been reports of FSGS patients with a high-risk APOL1 genotype, treated with IFN, who developed collapsing glomerulopathy ${ }^{15}$. In 2019 there was a case report of an

See APOL1 in lupus nephritis, page 1209

Personal non-commercial use only. The Journal of Rheumatology Copyright (C) 2020. All rights reserved. 
African American boy with SAVI (stimulator of IFN genesassociated vasculopathy with onset in infancy) - a disease of endogenous overproduction of type I IFN, APOLI high-risk genotype, and collapsing glomerulopathy. These reports all implicate IFN as the common, key link between APOL1 and collapsing glomerulopathy ${ }^{16}$.

The most extreme histologic manifestation of APOL1-associated nephropathy is collapsing glomerulopathy. First described in HIVAN, this aggressive lesion is characterized by segmental or global collapse and sclerosis of the glomerular tufts, with clinical manifestations of nephrotic syndrome, renal insufficiency, and rapid progression to $\mathrm{ESKD}^{13}$. There are an increasing number of reports of collapsing glomerulopathy in $\mathrm{LN}$, in the absence of infection ${ }^{17}$. Some of these reports make the link between APOL1 high-risk genotype and collapsing glomerulopathy in SLE ${ }^{18,19}$. One study identified 26 cases of collapsing glomerulopathy among 546 renal biopsies from African American patients with SLE. They observed an OR 5.4 (95\% CI 2.4-12.1) for developing collapsing glomerulopathy for the APOL1 high-risk genotype $(\mathrm{p}<0.001)$ compared to 1 or no risk alleles ${ }^{18}$. In the Vajgel, et al paper, the small number of patients with collapsing glomerulopathy precluded examination of the APOL1 association in their Brazilian cohort ${ }^{10}$.

Prior studies have investigated the associations between chronic kidney disease, cardiovascular disease (CVD), and APOL1 risk haplotypes, with differing results. In a single-center cohort study of 113 African American patients with SLE, the APOL1 risk allele frequency was $40 \%$, and the frequency of the high-risk genotype was $13 \%{ }^{20}$. Using chart review to assess and create composite indices for CVD endpoints, they observed that atherosclerotic CVD (defined as abdominal aortic aneurysm, angina, carotid artery disease, myocardial infarction, coronary artery disease, peripheral vascular disease, stroke, or vascular calcifications on imaging) was present in $30 \%$ of the cohort. The study reported more prevalent atherosclerotic CVD in those with 1 or more APOL1 risk alleles, compared to those with none (OR 7.1, 95\% CI 2.1-24.0, $\mathrm{p}=0.002$ ). Their models adjusted for smoking status, ESKD, body mass index, and hypertension. ESKD was present in $20 \%$ of those with a high-risk genotype, compared with $2-8 \%$ of those with 0 or 1 APOL1 risk alleles. In contrast, a large metaanalysis of 21,305 participants of African American ancestry, from 8 cohorts, did not find an association between APOL1 high-risk genotype (prevalence 13\%) and incident CVD or all-cause mortality ${ }^{21}$. This was after accounting for multiple risk factors for CVD and death, including kidney function (eGFR). Overall, there is limited evidence for a direct effect of APOL1 risk alleles on CVD outcomes independent of kidney function.

In recent years, we have learned a great deal about the relationship between APOL1, SLE, and kidney disease. Future research focused on how this knowledge affects prevention, prognosis, and therapy offers hope for improved care and outcomes for people with SLE at high risk of APOL1-associated disease.

LINDA T. HIRAKI, MD, FRCPS, ScD,

Assistant Professor, Pediatrics and Epidemiology,

Dalla Lana School of Public Health,

University of Toronto, and

Clinician Scientist,

Division of Rheumatology,

and Scientist, Child Health Evaluative Sciences

and Genetics and Genome Biology,

Research Institute,

The Hospital for Sick Children,

Toronto, Ontario, Canada.

Address correspondence to Dr. L.T. Hiraki, PGCRL, 686 Bay St., Toronto, Ontario M5G 0A4, Canada. E-mail: Linda.hiraki@ sickkids.ca. Dr. Hiraki is supported by research grants from the Canadian Institute of Health Research and The Arthritis Society.

\section{REFERENCES}

1. Kao WH, Klag MJ, Meoni LA, Reich D, Berthier-Schaad Y, Li M, et al. MYH9 is associated with nondiabetic end-stage renal disease in African Americans. Nat Genet 2008;40:1185-92.

2. Kopp JB, Smith MW, Nelson GW, Johnson RC, Freedman BI, Bowden DW, et al. MYH9 is a major-effect risk gene for focal segmental glomerulosclerosis. Nat Genet 2008;40:1175-84.

3. Freedman BI, Langefeld CD, Andringa KK, Croker JA, Williams $\mathrm{AH}$, Garner NE, et al. End-stage renal disease in African Americans with lupus nephritis is associated with APOL1. Arthritis Rheumatol 2014;66:390-6.

4. Kruzel-Davila E, Wasser WG, Skorecki K. APOL1 nephropathy: a population genetics and evolutionary medicine detective story. Semin Nephrol 2017;37:490-507.

5. Tzur S, Rosset S, Shemer R, Yudkovsky G, Selig S, Tarekegn A, et al. Missense mutations in the APOL1 gene are highly associated with end stage kidney disease risk previously attributed to the MYH9 gene. Hum Genet 2010;128:345-50.

6. Genovese G, Friedman DJ, Ross MD, Lecordier L, Uzureau P, Freedman BI, et al. Association of trypanolytic ApoL1 variants with kidney disease in African Americans. Science 2010;329:841-5.

7. Kopp JB, Nelson GW, Sampath K, Johnson RC, Genovese G, An P, Friedman D, et al. APOL1 genetic variants in focal segmental glomerulosclerosis and HIV-associated nephropathy. J Am Soc Nephrol 2011;22:2129-37

8. Lipkowitz MS, Freedman BI, Langefeld CD, Comeau ME, Bowden DW, Kao WH, et al. Apolipoprotein L1 gene variants associate with hypertension-attributed nephropathy and the rate of kidney function decline in African Americans. Kidney Int 2013;83:114-20.

9. Kasembeli AN, Duarte R, Ramsay M, Mosiane P, Dickens C, Dix-Peek T, et al. APOL1 risk variants are strongly associated with HIV-associated nephropathy in black South Africans. J Am Soc Nephrol 2015;26:2882-90.

10. Vajgel G, Lima S, Santana D, Oliveira C, Costa D, Anderson P, et al. A single APOL1 nephropathy variant increases risk of advanced lupus nephritis in Brazilians. J Rheumatol 2020;47:1209-17.

11. Freedman BI, Edberg JC, Comeau ME, Murea M, Bowden DW, Divers J, et al. The non-muscle Myosin heavy chain 9 gene (MYH9) is not associated with lupus nephritis in African Americans. Am J Nephrol 2010;32:66-72.

12. Lin CP, Adrianto I, Lessard CJ, Kelly JA, Kaufman KM, Guthridge $\mathrm{J}$, et al. Role of MYH9 and APOL1 in African and non-African

Personal non-commercial use only. The Journal of Rheumatology Copyright @ 2020 . All rights reserved. 
populations with lupus nephritis. Genes Immun 2012;13:232-8.

13. Friedman DJ, Pollak MR. Genetics of kidney failure and the evolving story of APOL1. J Clin Invest 2011;121:3367-74.

14. Friedman DJ. A brief history of APOL1: a gene evolving. Semin Nephrol 2017;37:508-13.

15. Nichols B, Jog P, Lee JH, Blackler D, Wilmot M, D'Agati V, et al. Innate immunity pathways regulate the nephropathy gene Apolipoprotein L1. Kidney Int 2015;87:332-42.

16. Abid Q, Best Rocha A, Larsen CP, Schulert G, Marsh R, Yasin S, et al. APOL1-associated collapsing focal segmental glomerulosclerosis in a patient with stimulator of interferon genes (STING)-associated vasculopathy with onset in infancy (SAVI). Am J Kidney Dis 2019 Oct 7 (E-pub ahead of print).

17. Salvatore SP, Barisoni LM, Herzenberg AM, Chander PN, Nickeleit V, Seshan SV. Collapsing glomerulopathy in 19 patients with systemic lupus erythematosus or lupus-like disease. Clin J Am Soc Nephrol 2012;7:914-25.
18. Larsen CP, Beggs ML, Saeed M, Walker PD. Apolipoprotein L1 risk variants associate with systemic lupus erythematosus-associated collapsing glomerulopathy. J Am Soc Nephrol 2013;24:722-5.

19. Kofman T, Narjoz C, Raimbourg Q, Loriot MA, Karras A, Roland $\mathrm{M}$, et al. Collapsing glomerulopathy associated lupus in a black female with homozygous APOL1 mutation. Lupus 2012; 21:1459-62.

20. Blazer A, Wang B, Simpson D, Kirchhoff T, Heffron S, Clancy RM, et al. Apolipoprotein L1 risk variants associate with prevalent atherosclerotic disease in African American systemic lupus erythematosus patients. PLoS One 2017;12:e0182483.

21. Grams ME, Surapaneni A, Ballew SH, Appel LJ, Boerwinkle E, Boulware LE, et al. APOL1 kidney risk variants and cardiovascular disease: an individual participant data meta-analysis. J Am Soc Nephrol 2019;30:2027-36.

J Rheumatol 2020;47:1155-7; doi:10.3899/jrheum.200038 